\title{
PEMERIKSAAN KESEHATAN DAN PEMBERIAN INFORMASI OBAT PADA KELOMPOK LANSIA St. ANGELA PAROKI KATEDRAL SAMARINDA
}

\author{
Bernarda Teting ${ }^{1}$, Katrina Tening ${ }^{2}$, Habel Roy Sulo ${ }^{3}$ \\ 1,2, Prodi D3 Keperawatan STIKES Dirgahayu Samarinda \\ ${ }^{3}$ Prodi S1 Farmasi STIKES Dirgahayu Samarinda \\ Email : tetingb@yahoo.com
}

\begin{abstract}
ABSTRAK
Perubahan organ tubuh merupakan proses penuaan yang tidak dapat kita hindari dan tolak oleh setiap manusia. Kelompok lansia memerlukan perhatian khusus agar mereka tetap dalam keadaan yang sehat selalu. Pemeriksaan kesehatan perlu dilakukanan secara rutin untuk menjaga kesehatan agar tetap terkontrol, sehingga secara umum akan berpengaruh pada aktivitas kegiatan sehari-harinya. Tujuan dari kegiatan ini adalah melakukan pemeriksaan kesehatan tekanan darah dan pemberian informasi obat kepada lansia St. Angela Paroki Katedral Samarinda. Metode yang digunakan dengan pemeriksaan kesehatan dan penyuluhan pemberian informasi obat. Hasil pemeriksaan kesehatan yang telah dilaksanakan diperoleh tekanan darah sistole tertinggi sebesar $216 \mathrm{mmHg}$ dan sistole terendah sebesar $110 \mathrm{mmHg}$. Sedangkan untuk tekanan darah diastole tertinggi sebesar $116 \mathrm{mmHg}$ dan diastole terendah sebesar $60 \mathrm{mmHg}$.
\end{abstract}

\section{Kata Kunci: Pemeriksaan Kesehatan, Pemberian Informasi Obat, Kelompok Lansia}

\begin{abstract}
Organ changes are an aging process that we cannot avoid and reject by every human being. Elderly groups need special attention to keep them in a healthy state always. Healths check-ups need to be routinely performed to keep your health controlled, so that it will generally affect your daily activities. The purpose of this activity is to conduct health screening of blood pressure and the provision of drug information to erlderly St. Angela Paroki Katedral Samarinda. Method used with medical examination and extension of the introduction of drug information. The results of the medical examination have been carried out obtained by the highest blood pressure of $216 \mathrm{mmHg}$ and the lowest sistole of $110 \mathrm{mmHg}$ as for the hingest diastole blood pressure of pressure of $116 \mathrm{mmHg}$ and the lowest diastole of $60 \mathrm{mmHg}$.
\end{abstract}

Key Words: health screening, drug delivery, elderly groups

\section{PENDAHULUAN}

Proses penuaan merupakan siklus kehidupan yang ditandai dengan tahapan terjadinya penurunan berbagai fungsi organ tubuh yang ditandai dengan semakin rentannya tubuh terhadap berbagai serangan penyakit yang dapat menyebabkan kematian. Beberapa penyakit tersebut diantaranya kardiovaskuler dan pembuluh darah, gangguan pernapasan, gangguan pencernaan, endoktrin dan sebagainya. Hal tersebut disebabkan peningkatan usia sehingga terjadi perubahan struktur dan fungsi sel, jaringan serta sistem organ tubuh. Perubahan tersebut pada umumnya mempengaruhi pada kemunduran kesehatan fisik dan psikis yang pada akhirnya akan berpengaruh pada ekonomi dan sosial para lansia, sehingga secara umum akan berpengaruh pada aktivitas kegiatan sehari-harinya.

Batasan umur pada usia lanjut dari waktu ke waktu berbeda. Menurut World Health Organitation (WHO) lansia meliputi : a. usia pertengahan (middle age) antara usia 45 sampai 59 tahun; b. lanjut usia (elderly) antara usia 60 sampai 74 tahun; c. lanjut usia tua (old) antara usia 75 sampai 90 tahun; d. usia sangat tua (very old) diatas usia 90 
tahun. berdasarkan data tersebut maka perhatian pada masalah kelompok lansia memerlukan perhatian khusus. Penampilan penyakit pada lanjut usia (lansia) sering berbeda dengan orang dewasa atau muda, karena penyakit pada lansia merupakan gabungan dari kelainan-kelainan yang timbul akibat penyakit dan proses menua, yaitu proses menghilangnya secara perlahan-lahan kemampuan jaringan untuk memperbaiki diri atau mengganti diri serta mempertahankan struktur dan fungsi normalnya, sehingga tidak dapat bertahan terhadap penyakit (termasuk infeksi) dan memperbaiki kerusakan yang diderita.

Pada usia lanjut 90\% tingkat kesegaran jasmaninya rendah terutama pada komponen daya tahan kardio respirasi dan kekuatan otot. Maka hal yang dapat dilakukan lansia untuk memperbaiki fungsi kardiovaskular dan menimbulkan perasaan segar adalah melakukan olahraga adalah salah satu bentuk latihan fisik yang memberikan pengaruh yang baik/positif terhadap kemampuan fisik seseorang apabila dilakukan secara baik dan benar. Melakukan latihan fisik yang baik dapat bermanfaat sebagai upaya promotif, preventif, kuratif dan rehabilitative dan apabila ditinjau secara fisiologi, psikologi dan sosial memberikan dampak secara langsung dan jangka panjang.

Pengetahuan lansia tentang penggunaan obat yang baik dan benar sangat minim, bahaya penggunaan obat yang tidak benar dapat mengakibatkan hal yang tidak diinginkan. Peran serta tenaga kefarmasian dalam memberikan informasi tentang penggunaan obat secara baik dan benar sangat diharapkan dapat meningkatkan taraf hidup lansia. Agar para lansia mendapatkan informasi Berdasarkan hasil kegiatan yang telah dilakukan selama pelaksanaan Pengabdian Kepada Masyarakat pada pemeriksaan kesehatan dan pemberian yang akurat tentang obat maka dibutuhkan peran serta Apoteker dalam hal ini. Hal tersebut dapat dilakukan dengan memberikan penyuluhan tentang penggunaan obat kepada para lansia dengan harapan dapat diterapkan dalam kehidupan sehari-harinya, sehingga lansia dapat mengetahui bahaya dan manfaat obat dengan tepat dalam terapi pengobatan.

Jumlah kelompok lansia St. Angela Paroki Katedral Samarinda berjumlah sekitar 30 orang lansia. Berdasarkan data tersebut maka pemeriksaan kesehatan lansia dan pemberian obat perlu mendapatkan perhatian khusus dan menjadi program Kemitraan Masyarakat STIKES Dirgahayu Samarinda.

\section{METODE}

Pelaksanaan kegiatan pengabdian masyarakat ini menggunakan 2 metode kegiatan, sebagai berikut:

a. Melaksanaan pemeriksaan kesehatan dalam kegiatan ini dilakukan dengan cara memeriksa kesehatan glukosa darah pada lansia dan memeriksa tekanan darah pada lansia.

b. Melakukan Pemberian Informasi Obat yang baik dan benar pada Lansia dengan cara melakukan penyuluhan, membagikan leaflet dan diskusi tanya jawab dengan lansia seputaran obat dan kesehatan.

Alat dan Bahan yang digunakan

a. Alat cek tekanan darah merk omron

b. Alat cek glucosa merk easy touch

c. Alat stick glucosa merk easy touch

d. Blood lancet merk lotus

e. Alkohol swab merk sensi

f. Tissue merk paseo

g. Leaflet dan materi Pemberian Informasi Obat (PIO)

\section{HASIL DAN PEMBAHASAN}

informasi obat pada kelompok lansia St. Angela Paroki Katedral Samarinda Tahun 2018 didapatkan hasil sebagai berikut ini : 


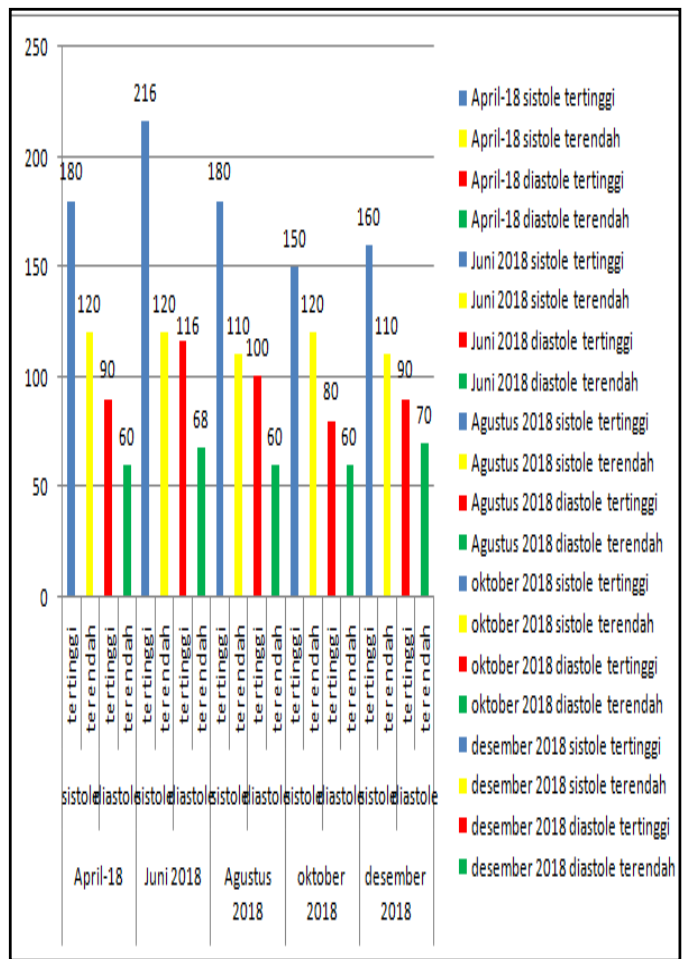

Gambar 1. Hasil Pemeriksaan Tekanan Darah Kelompok Lansia St. Angela Paroki Katedral Samarinda

Pelaksanaan PKM dilaksanakan sebanyak 6 Kali dengan rincian 5 kali kegiatan pemeriksaan kesehatan dan 1 kali kegiatan penyuluhan Pemberian Informasi Obat yang dilakukan oleh Apoteker. Hasil pemeriksaan kesehatan yang telah dilaksanakan diperoleh tekanan darah sistole tertinggi sebesar $216 \mathrm{mmHg}$ dan sistole terendah sebesar $110 \mathrm{mmHg}$. Sedangkan untuk tekanan darah diastole tertinggi sebesar 116 $\mathrm{mmHg}$ dan diastole terendah sebesar 60 $\mathrm{mmHg}$.

Hasil pemeriksaan kesehatan yang telah dilakukan menunjukkan bahwa tekanan darah Sistole diatas normal $140 \mathrm{mmHg}$ dan Diastole diatas normal $90 \mathrm{mmHg}$. Hal dapat dikatakan bahwa kelompok lansia menderita Hipertensi dan perlu mendapatkan terapi pengobatan hipertensi. Penyuluhan Pemberian Informasi Obat dilakukan terhadap penggunaan obat Hipetensi secara baik dan benar. Peningkatan tekanan darah yang berlangsung dalam jangka waktu lama (persisten) dapat menimbulkan kerusakan pada ginjal (gagal ginjal), jantung (penyakit jantung koroner) dan otak (menyebabkan stroke) apabila tidak dideteksi secara dini dan mendapatkan pengobatan yang tepat dan benar. Banyak pasien hipertensi dengan tekanan darah tidak terkontrol dan jumlahnya terus meningkat oleh sebab itu peran serta semua pihak sangat diperlukan.

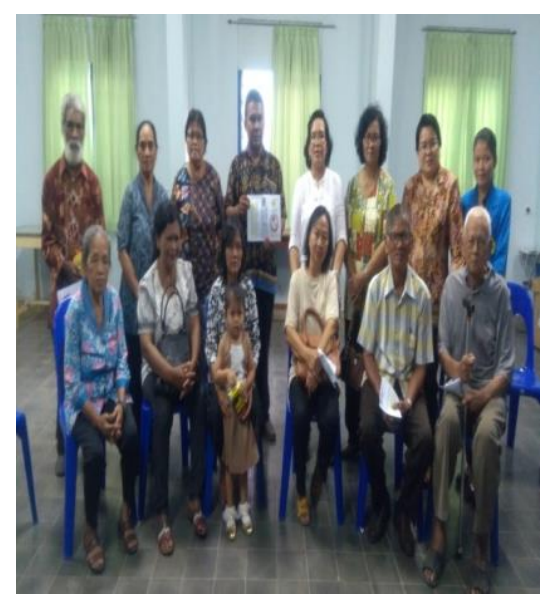

Gambar 2. Foto bersama dengan lansia St. Angela Paroki Katedral Samarinda

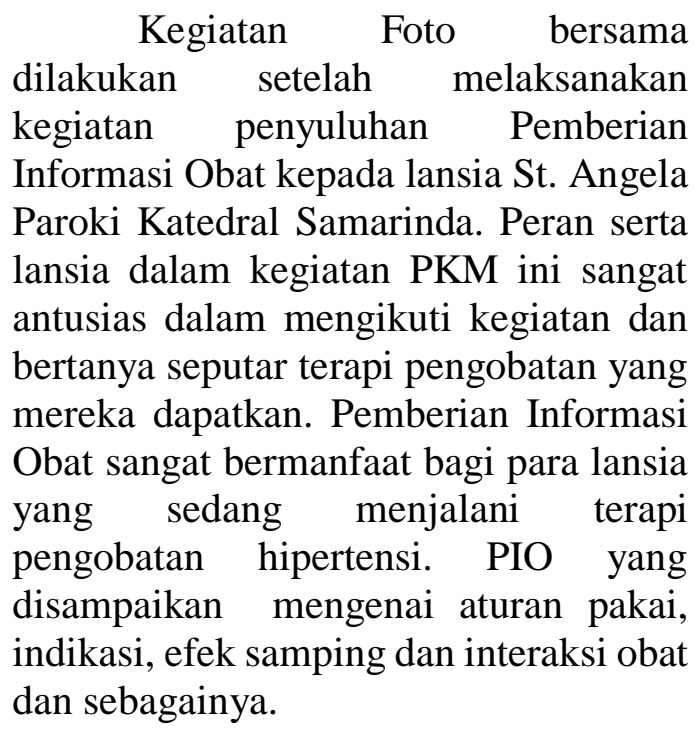




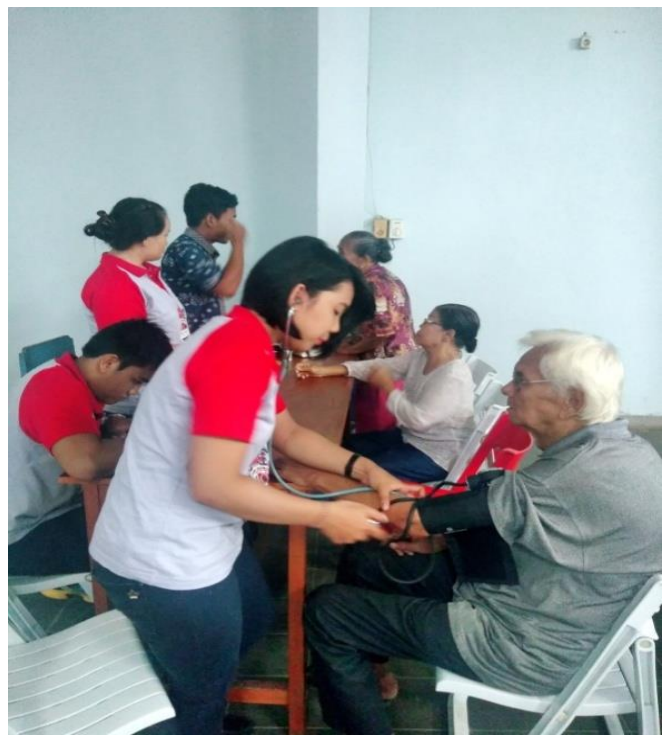

Gambar 3. Pemeriksaan Kesehatan Tekanan Darah Lansia St. Angela Paroki Katedral Samarinda

Pemeriksaan kesehatan tekanan darah lansia St. Angela dilakukan sebanyak 5 kali pada bulan April, Juni, Agustus, Oktober dan Desember 2018. Hasil Pemeriksaan Bulan April untuk tekanan darah Sistole tertinggi $180 \mathrm{mmHg}$ dan terendah $120 \mathrm{mmHg}$, diastole tertinggi $90 \mathrm{mmHg}$ dan terendah $60 \mathrm{mmHg}$. Bulan Juni untuk tekanan darah Sistole tertinggi $216 \mathrm{mmHg}$ dan terendah 120 $\mathrm{mmHg}$, diastole tertinggi $116 \mathrm{mmHg}$ dan terendah $68 \mathrm{mmHg}$. Bulan Agustus untuk tekanan darah Sistole tertinggi 180 $\mathrm{mmHg}$ dan terendah $110 \mathrm{mmHg}$, diastole tertinggi $100 \mathrm{mmHg}$ dan terendah $60 \mathrm{mmHg}$. Bulan Oktober untuk tekanan darah Sistole tertinggi 150 $\mathrm{mmHg}$ dan terendah $120 \mathrm{mmHg}$, diastole tertinggi $80 \mathrm{mmHg}$ dan terendah $60 \mathrm{mmHg}$. Bulan Desember untuk tekanan darah Sistole tertinggi 160 $\mathrm{mmHg}$ dan terendah $110 \mathrm{mmHg}$, diastole tertinggi $90 \mathrm{mmHg}$ dan terendah $70 \mathrm{mmHg}$. Hal ini menunjukkan bahwa tekenan darah sistole > $140 \mathrm{mmHg}$ dan diastole > 90 mmHg, sehingga dapat dikatakan bahwa para lansia St.Angela Paroki Katedral Samarinda menderita
Hipertensi,dikarena usia yang cukup terlalu tua dan diharapkan mereka untuk mengkonsumsi makanan yang sehat dan istirahat teratur, rajin berolahraga dan menjaga agar tidak mudah stres.

\section{KESIMPULAN DAN SARAN}

Program Kegiatan Masyarakat (PKM) Program Kegiatan Masyarakat (PKM) yang telah dilaksanakan selama tahun 2018 yang bertempat di Aula Rumah Sakit Dirgahayu Samarinda sebagai bentuk pelaksanaan Tridarma Perguruan Tinggi Stikes Dirgahayu Samarinda dengan judul Pemeriksaan Kesehatan Dan Penyuluhan Tentang Dagusibu Pada Kelompok Lansia St. Angela Paroki Katedral Samarinda Tahun 2018 telah terlaksanakan dengan baik dan memberikan manfaat bagi lansia demi untuk meningkatkan derajat kesehatan. Peran serta Apoteker dalam memberikan informasi tentang obat yang baik dan benar kepada Kelompok Lansia St. Angela Paroki Katedral Samarinda sangat memberikan manfaat yang besar dalam hal untuk mendapatkan, menggunakan, menyimpan dan membuang obat yang baik dan benar.

Saran sebagai berikut:

a. Diharapkan keaktifan lansia untuk hadir pada kegiatan PkM selanjutnya, agar dapat lebih aktif lagi.

b. Diharapkan peran aktif dari lansia untuk dapat menjaga pola hidup sehat dengan cara mengkonsumsi obat yang benar, makan makanan bergizi dan rajin berolahraga.

c. Agar lansia untuk menghindari stress yang dapat menjadi pemicu penyakit.

d. Agar lansia mendapatkan KIE tentang PIO yang dilakukan secara rutin oleh Apoteker 


\section{UCAPAN TERIMA KASIH}

Terima kasih kami sampaikan kepada STIIKES Dirgahayu Samarinda melalui Unit Penelitian dan Pengebadian Masyarakat (UPPM) dan Kelompok Lansia ST. Angela Paroki Katedral Samarinda sehingga penyususn dapat melaksanakan kegiatan PKM dengan baik.

\section{DAFTAR PUSTAKA}

Badan Pusat Statistik (2015). Data Kependudukan . Samarinda: BPS Kota Samarinda.

Anonim. Pedoman Pelaksanaan Gerakan Keluarga Sadar Obat. Pengurus Pusat Ikatan Apoteker Indonesia; 2014

Kemenkes RI., (2013). Buletin Lansia. Diakses pada tanggal 15 Maret 2018 dari http://www.depkes.go.id/download. php?file=pusdatin/buletin-lansia.pdf

Kemensos RI., (2013). Kebijakan Dan Program Pelayanan Sosial Lansia. Jakarta: Depsos RI. Diakses pada tanggal 15 Maret2018 dari http://www.depsos.go.id

Kemenkes RI.(2006). Pedoman Obat Bebas dan Bebas Terbatas. Jakarta. WHO. Definition of an Older or Elderly Person. Tersedia dari http://www.who.int/. Diakses tanggal 15maret 2020 
